\title{
Pathogen-specific antigen target for production of antibodies produced by comparative genomics
}

\author{
This article was published in the following Dove Press journal: \\ Antibody Technology Journal \\ 9 May 2014 \\ Number of times this article has been viewed
}

\section{Amanda A Lathrop ${ }^{1,2}$ \\ Taylor W Bailey² \\ Kwang-Pyo Kim²,3 \\ Arun K Bhunia ${ }^{2,4}$}

'Food Science and Nutrition Department, California Polytechnic State University, San Luis Obispo, CA, ${ }^{2}$ Molecular Food Microbiology Laboratory, Department of Food Science, Purdue University, West Lafayette, IN, USA; ${ }^{3}$ Department of Food Science and Technology, College of Agriculture and Life Sciences, Chonbuk National University, Jeonbuk, Republic of Korea; ${ }^{4}$ Department of Comparative Pathobiology, Purdue University, West Lafayette, IN, USA

Correspondence: Arun K Bhunia Molecular Food Microbiology Laboratory, Department of Food Science, Purdue University, 745 Agriculture Mall Drive, West Lafayette, IN 47907, USA

Tel +l 7654945443

Fax +l 7654947953

Email bhunia@purdue.edu
Abstract: Listeria monocytogenes continues to be a major public health risk and there is a need for improved rapid detection methods. New and highly specific L. monocytogenes antibodies are needed to advance current detection and meet the needs of industry. This research compared the L. monocytogenes genome with that of L. innocua (a nonpathogenic species of Listeria) and identified nine surface proteins specific to L. monocytogenes. Protein sequences were collected from the database and properties such as hydropathy profile and transmembrane topology were analyzed using TMpred software. Nine peptide sequences were chosen, and synthetic peptides were made and administered to rabbits for antibody production. All nine antibodies were screened against a panel of L. monocytogenes, nonpathogenic Listeria, and nonListeria bacteria. Two of the nine antibodies, ie, the Lm404 and LmC639 polyclonal antibodies, showed a specific reaction to $L$. monocytogenes internalin B and actin polymerization protein, respectively, and were characterized further by enzyme-linked immunosorbent assay, Western blot, and transmission electron microscopy. In Western blot, both antibodies reacted with the targeted protein and did not cross-react with other Listeria spp. The Lm404 polyclonal antibody showed a high reaction with the panel of 41 L. monocytogenes strains while the LmC639 polyclonal antibody showed a weak reaction. Both the Lm404 and LmC639 polyclonal antibodies showed potential for use in immunoassays for specific detection of L. monocytogenes. This study further indicates that comparative genomics could be used to select pathogen-specific antigen for antibody production.

Keywords: comparative genomics, Listeria monocytogenes, polyclonal antibodies, internalin B, actin polymerization protein, proteomics

\section{Introduction}

Listeria monocytogenes is an invasive foodborne pathogen that has historically been a major problem in the meat and dairy industries and has now become an issue in the produce industry. ${ }^{1,2}$ In recent years, this organism caused several outbreaks in multiple states in the United States, with numerous fatalities including stillbirths and abortions. ${ }^{3-6}$ The food industry is under constant pressure to detect and eliminate L. monocytogenes from finished products and the processing environment. To successfully manage this organism, specific and sensitive detection of L. monocytogenes is critical for ensuring food safety. Conventional culture methods, such as those as outlined by the US Department of Agriculture and US Food and Drug Administration, are reliable but take about 5-7 days for detection and confirmation of L. monocytogenes from foods. ${ }^{7}$ Antibody-based immunoassays are rapid, but most commercially available antibody-based assay kits are Listeria genus-specific because suitable antibodies specific for L. monocytogenes are lacking. ${ }^{8}$ 
The most common Listeria antigens used for antibody production have been flagella, listeriolysin $\mathrm{O}$, phosphatidylcholine-specific phospholipase $\mathrm{C}(68 \mathrm{kDa})$, and p60 proteins. ${ }^{8-10}$ Many of these antibodies react to antigens that are either shared by pathogenic and nonpathogenic Listeria species or only specific to certain serotypes, or their expression is affected by various environmental factors, such as $\mathrm{pH}$, temperature, and carbon sources. ${ }^{11-15}$ Monoclonal antibodies developed to listeriolysin $\mathrm{O}$ and phosphatidylcholinespecific phospholipase $\mathrm{C}$ from $L$. monocytogenes showed cross-reaction with $L$. ivanovii. ${ }^{16} \mathrm{~A}$ monoclonal antibody (EM-7G1) specific for L. monocytogenes was developed against a $66 \mathrm{kDa}$ surface antigen; however, the monoclonal antibody failed to react with all but three serotypes (3b, 4a, $4 \mathrm{c})$ of $L$. monocytogenes. ${ }^{17}$ Sølve et $a \mathrm{a}^{18}$ also developed monoclonal antibodies that reacted with live L. monocytogenes and L. innocua but showed no reaction with the other Listeria species tested. The invasion-associated protein $\mathrm{p} 60$ was used to develop polyclonal antibodies and showed reaction with all Listeria species, ${ }^{19}$ and a monoclonal antibody against the recombinant p60 detected L. monocytogenes and other Listeria spp. ${ }^{10}$ L. monocytogenes $4 \mathrm{~b}$ specific monoclonal antibodies showed cross reaction with serotype $4 \mathrm{~d}$ and $4 \mathrm{e}$ and L. innocua strains. ${ }^{20}$ Paoli et $\mathrm{al}^{21}$ developed a singlechain $\mathrm{Fv}$ antibody to L. monocytogenes that reacted with no other Listeria species, but failed to react with several serovars of L. monocytogenes. A polyclonal antibody against internalin B was also reported, and this antibody was used in a surface plasmon resonance sensor for detection of $L$. monocytogenes. However, the characteristics of this antibody's reaction with different $L$. monocytogenes strains or other Listeria species are unknown. ${ }^{22} \mathrm{~A}$ sandwich enzymelinked immunosorbent assay (ELISA) has been developed using a flagella-specific monoclonal antibody for detection of Listeria species. ${ }^{9}$ Recently, a monoclonal antibody against internalin A was found to be highly specific and was used for detection of L. monocytogenes and L. ivanovii in a fiber optic immunosensor. ${ }^{23}$ While many antibodies have been developed for L. monocytogenes, there is still a need for more specific and highly reactive antibodies.

The genome sequences of L. monocytogenes and L. innocua have been published. ${ }^{24-26}$ Genetic analysis indicated that there were $270 \mathrm{~L}$. monocytogenes-specific and $149 \mathrm{~L}$. innocua-specific genes, ${ }^{25}$ and genes for major virulence factors, such as internalin $A$, internalin $B$, actin polymerization (ActA), listeriolysin $\mathrm{O}, \mathrm{PlcA}$, and $\mathrm{PlcB}$ in L. monocytogenes were conserved. ${ }^{26}$ Comparative genome sequence analyses further revealed that there were 22 surface proteins unique to L. monocytogenes. Of these 22 proteins, five belonged to the internalin multigene family, one was ActA protein, and the remaining 16 were unknown. ${ }^{27}$ Our goal was to develop antibodies against these proteins for use in immunoassays for specific detection of L. monocytogenes. Furthermore, we also verified if the antibody-specific epitopes would be surfaceexposed for interaction with antibody in whole cell ELISA and immunoelectron microscopy. This study shows that comparative genomics could be used as a tool to select pathogen-specific antigens for antibody production.

\section{Materials and methods}

\section{Cultures and media}

Frozen stock cultures of all Listeria species and other nonListeria cultures (Tables 1-3) were subcultured in brain heart infusion broth and maintained on stabs of brain heart infusion agar (Becton Dickinson, Sparks, MD, USA) for 2-3 months at room temperature. For fresh cultures, samples of the stabs were inoculated into brain heart infusion broth and grown at $37^{\circ} \mathrm{C}$ for $18-20$ hours. L. monocytogenes DP-L2723 (containing recombinant ActA His-tagged protein, a gift from Daniel Portnoy, University of California, Berkeley, CA, USA) was grown in Luria-Bertani broth with $10 \mu \mathrm{g} / \mathrm{mL}$ of chloramphenicol overnight and shaking. ${ }^{28}$ Internalin B containing Escherichia coli strain BL21 (DE) with pET28b-1 (a gift from Pascale Cossart, Institut Pasteur, Paris, France) was grown overnight with shaking in Luria-Bertani broth with $30 \mu \mathrm{g} / \mathrm{mL}$ of kanamycin. ${ }^{29}$

\section{Protein sequence analysis and selection of unique peptide epitope as an immunogen}

Comparative genome sequencing of $L$. monocytogenes and $L$. innocua indicated that there existed about 22 unique surface proteins of $L$. monocytogenes, the orthologs of which were absent in a nonpathogenic L. innocua $\operatorname{strain} .{ }^{25}$ From the 22 unique surface proteins, nine were selected (Table 1). Properties such as hydropathy profile based on the Kyte and Doolittle hydrophobicity scale ${ }^{30}$ and transmembrane topology were analyzed using the ProtScale and TMpred programs (ExPASy software, Swiss Institute of Bioinformatics, Lausanne, Switzerland). This information was used to select putative surface-exposed 20-mer peptide sequences. A Protein BLAST search (BLASTP) was used to confirm the uniqueness of the chosen peptides in the National Center for Biotechnology Information database. 
Table I Selected unique target peptide sequences of Listeria monocytogenes obtained from Listeria genome sequence database as immunogens and respective antibody titers against peptide antigens and whole cells

\begin{tabular}{|c|c|c|c|c|c|c|c|}
\hline \multirow{2}{*}{$\begin{array}{l}\text { Target } \\
\text { protein }\end{array}$} & \multirow{2}{*}{$\begin{array}{l}\text { Protein size } \\
\text { (amino acids) }\end{array}$} & \multirow{2}{*}{$\begin{array}{l}\text { Molecular } \\
\text { mass (kDa) }\end{array}$} & \multirow[t]{2}{*}{ Function } & \multirow{2}{*}{$\begin{array}{l}\text { Target } 20 \text {-mer peptide } \\
\text { sequence }^{\mathrm{a}}\end{array}$} & \multirow{2}{*}{$\begin{array}{l}\text { Antibody } \\
\text { designation }\end{array}$} & \multicolumn{2}{|c|}{ Antibody titer ${ }^{b}$} \\
\hline & & & & & & Peptide & Whole cells \\
\hline Internalin A & 800 & 80 & Invasion & 276 TDLDLANNQISNLAPLSGLT & LmA800 & 288,000 & 160 \\
\hline Internalin B & 630 & 63 & Invasion & 228 GLKNLDVLELFSQECLNKPI & Lm404 & 163,840 & 640 \\
\hline Internalin $\mathrm{H}$ & 548 & 55 & Unknown & I8I PLAGLTNLQYLSIGNAQVSD & $\mathrm{LmH} 548$ & 16,000 & 160 \\
\hline ActA protein & 639 & 90 & Cell-to-cell spread & II 0 QTENAAINEEASGADRPAIQ & LmC639 & 88,000 & 160 \\
\hline Lmo0460 & 689 & 69 & $\begin{array}{l}\text { Putative } \\
\text { membrane protein }\end{array}$ & 547 LNQDCTNKFDFSLPADASIT & Lm405 & 40,960 & 160 \\
\hline LmolII5 & 862 & 86 & $\begin{array}{l}\text { Hypothetical } \\
\text { protein }\end{array}$ & 416 HSPNLYLGEYQAVEVSAPAG & Lm406 & 160 & NT \\
\hline $\begin{array}{l}\text { Lmol } 290 \\
\text { (internalin K) }\end{array}$ & 598 & 60 & $\begin{array}{l}\text { Escape from } \\
\text { autophagy }\end{array}$ & 302 SKTDFDNLEKMEYNARIDLS & $\operatorname{Lm} \mid 290$ & 135,000 & 160 \\
\hline Lmo2026 & 626 & 63 & $\begin{array}{l}\text { Peptidoglycan } \\
\text { binding protein }\end{array}$ & 250 LTPDKTNLGLKSNIPLFSQH & Lm407 & 40,960 & 640 \\
\hline Lmo2085 & 562 & 56 & $\begin{array}{l}\text { Peptidoglycan } \\
\text { binding protein }\end{array}$ & 420 FKQDEANKKGLANAVFDVKS & Lm408 & 81,920 & 160 \\
\hline
\end{tabular}

Notes: aNumber represents the starting position of the peptide in the protein sequence; biter is the dilution of the antibody that gave $50 \%$ of the maximum achieved response on indirect enzyme-linked immunosorbent assay. The peptide concentration was $15 \mu \mathrm{g}$ per well, and that of bacterial cells was $\sim 10^{8}$ colony-forming units per well. Abbreviation: NT, not tested.

\section{Peptide synthesis and antibody production and purification}

Peptides for internalin B, Lmo0460, Lmo1115, Lmo2026, and Lmo2085 that consisted of 20 amino acids (Table 1) with an additional cysteine residue (needed for conjugation with keyhole limpet hemocyanin $[\mathrm{KLH}])$ were synthesized in the Laboratory for Macromolecular Structure at Purdue University, purified by high-performance liquid chromatography using a $\mathrm{C}-18$ reverse phase column, and subjected to mass spectrometric analyses. Each purified peptide (2 mg) from Purdue University was conjugated with $2 \mathrm{mg}$ of KLH using a 77511 kit $\left(\right.$ Imject $^{\circledR}$, maleimide-activated mcKLH, Pierce, Rockford, IL, USA) and injected subcutaneously into two rabbits for antibody production (Animal Science Department, Purdue University). Rabbits were injected with $150 \mu \mathrm{g}$ of conjugated peptide every 3 weeks, and after the third immunization, the serum was collected every 3 weeks until the rabbits were terminally bled (after four bleeds). The remaining peptides for internalin A, internalin H, ActA, and Lmo1290 (internalin $\mathrm{K}$ ) were synthesized, conjugated, and antibodies

Table 2 Reaction patterns of eight antibodies to different Listeria and non-Listeria cultures on indirect enzyme-linked immunosorbent assay (absorbance $490 \mathrm{~nm}$ )

\begin{tabular}{|c|c|c|c|c|c|c|c|c|}
\hline Cultures & Lm404 & Lm408 & Lm407 & Lm405 & LmA800 & LmC639 & Lm I 290 & LmH548 \\
\hline Listeria monocytogenes V7 & $3.97 \pm 0.05$ & $1.01 \pm 0.25$ & $0.29 \pm 0.08$ & $0.82 \pm 0.03$ & $0.87 \pm 0.05$ & $0.69 \pm 0.31$ & $0.75 \pm 0.38$ & $1.56 \pm 0.00$ \\
\hline L. monocytogenes F4244 & $1.27 \pm 0.21$ & $0.90 \pm 0.12$ & $0.38 \pm 0.14$ & $0.76 \pm 0.02$ & $0.24 \pm 0.06$ & $0.34 \pm 0.05$ & $0.5 I \pm 0.08$ & $0.32 \pm 0.06$ \\
\hline L. monocytogenes Scott A & $0.18 \pm 0.04$ & $0.40 \pm 0.13$ & $0.14 \pm 0.04$ & $0.24 \pm 0.02$ & $0.13 \pm 0.06$ & $0.12 \pm 0.06$ & $0.25 \pm 0.11$ & $0.14 \pm 0.05$ \\
\hline L. innocua LA-I & $0.27 \pm 0.12$ & $0.76 \pm 0.05$ & $0.32 \pm 0.12$ & $0.74 \pm 0.0 \mathrm{I}$ & $0.26 \pm 0.03$ & $0.20 \pm 0.04$ & $0.5 I \pm 0.12$ & $0.29 \pm 0.06$ \\
\hline L. innocua F4248 & $0.22 \pm 0.08$ & $0.74 \pm 0.15$ & $0.33 \pm 0.13$ & $0.9 \mathrm{I} \pm 0.03$ & $0.24 \pm 0.06$ & $0.19 \pm 0.03$ & $0.58 \pm 0.14$ & $0.38 \pm 0.10$ \\
\hline L. grayi ATCCI9I20 & $0.44 \pm 0.10$ & $1.04 \pm 0.06$ & $0.33 \pm 0.06$ & $0.95 \pm 0.03$ & $0.28 \pm 0.10$ & $0.42 \pm 0.09$ & $0.70 \pm 0.08$ & $0.49 \pm 0.02$ \\
\hline L. ivanovii SE98 & $0.29 \pm 0.13$ & $0.62 \pm 0.11$ & $0.25 \pm 0.05$ & $0.39 \pm 0.02$ & $0.19 \pm 0.06$ & $0.15 \pm 0.06$ & $0.4 I \pm 0.05$ & $0.23 \pm 0.07$ \\
\hline L. seeligeri SE3 I & $0.30 \pm 0.06$ & $0.40 \pm 0.07$ & $0.18 \pm 0.06$ & $0.3 \mathrm{I} \pm 0.0 \mathrm{I}$ & $0.27 \pm 0.11$ & $0.25 \pm 0.18$ & $0.4 I \pm 0.18$ & $0.22 \pm 0.07$ \\
\hline L. welshimeri ATCC35897 & $0.26 \pm 0.05$ & $0.79 \pm 0.12$ & $0.30 \pm 0.06$ & $0.53 \pm 0.10$ & $0.22 \pm 0.04$ & $0.34 \pm 0.03$ & $0.60 \pm 0.16$ & $0.31 \pm 0.05$ \\
\hline L. marthii BAA-I595 & $0.34 \pm 0.01$ & $0.76 \pm 0.03$ & $1.14 \pm 0.04$ & $1.59 \pm 0.11$ & $0.76 \pm 0.03$ & $0.66 \pm 0.06$ & NT & NT \\
\hline L. rocourtiae CIPI09804 & $0.37 \pm 0.01$ & $1.11 \pm 0.02$ & $0.69 \pm 0.02$ & $1.55 \pm 0.15$ & $1.11 \pm 0.02$ & $0.7 I \pm 0.0 I$ & NT & NT \\
\hline Bacillus cereus $4 \mathrm{AC}$ & $0.7 \mathrm{I} \pm 0.06$ & $0.82 \pm 0.04$ & $0.30 \pm 0.11$ & $0.80 \pm 0.05$ & $0.25 \pm 0.04$ & $0.29 \pm 0.02$ & $0.60 \pm 0.11$ & $0.26 \pm 0.04$ \\
\hline Citrobacter freundii ATCC 3624 & $0.34 \pm 0.16$ & $0.48 \pm 0.02$ & $0.45 \pm 0.24$ & $1.00 \pm 0.05$ & $0.29 \pm 0.08$ & $0.48 \pm 0.23$ & $0.74 \pm 0.35$ & $0.35 \pm 0.04$ \\
\hline Escherichia coli ATCC5I739 & $1.37 \pm 0.28$ & $2.26 \pm 0.40$ & $3.07 \pm 0.4 \mathrm{I}$ & $2.90 \pm 0.20$ & $2.0 \mathrm{I} \pm 0.33$ & $1.77 \pm 0.22$ & $2.48 \pm 0.33$ & $3.27 \pm 0.11$ \\
\hline Salmonella enterica serovar & $2.24 \pm 0.07$ & $2.59 \pm 0.32$ & $3.14 \pm 0.25$ & $3.43 \pm 0.07$ & $2.16 \pm 0.34$ & $2.13 \pm 0.30$ & $2.84 \pm 0.17$ & $3.32 \pm 0.10$ \\
\hline Enteritidis ATCCI3096 & & & & & & & & \\
\hline
\end{tabular}

Notes: Bacterial cell concentration used: $10^{8}$ colony-forming units per well. Antibody dilutions used: Lm404 and Lm407 at I:I,000; Lm407 and Lm405 at I:300; and LmA800, $\mathrm{LmC639}, \mathrm{Lm} 1290$, and $\mathrm{LmH} 48$ at I: 100.

Abbreviation: NT, not tested. 
Table 3 Analysis of Lm404 and LmC639 polyclonal antibody reaction patterns to different Listeria monocytogenes strains grown in brain heart infusion broth on indirect enzyme-linked immunosorbent assay (absorbance $490 \mathrm{~nm}$ )

\begin{tabular}{|c|c|c|c|}
\hline $\begin{array}{l}\text { Listeria monocytogenes } \\
\text { strain }\end{array}$ & Serotype & Lm404a & $\operatorname{LmC639^{b}}$ \\
\hline SLCC 2482 & 7 & $0.89 \pm 0.13$ & $0.18 \pm 0.06$ \\
\hline V37CE & $\mathrm{I} / 2 \mathrm{a}$ & $0.73 \pm 0.09$ & $0.37 \pm 0.03$ \\
\hline $103 M$ & $\mathrm{I} / 2 \mathrm{a}$ & $0.60 \pm 0.10$ & $1.01 \pm 0.13$ \\
\hline$|7|$ & $\mathrm{I} / 2 \mathrm{a}$ & $0.75 \pm 0.02$ & $0.33 \pm 0.02$ \\
\hline F4263 & $\mathrm{I} / 2 \mathrm{a}$ & $0.64 \pm 0.20$ & $0.73 \pm 0.06$ \\
\hline ATCC 35152 & $\mathrm{I} / 2 \mathrm{a}$ & $0.5 I \pm 0.05$ & $0.23 \pm 0.05$ \\
\hline ATCC 15313 & $\mathrm{I} / 2 \mathrm{a}$ & $0.68 \pm 0.02$ & $0.21 \pm 0.08$ \\
\hline FSL R2-499 & $\mathrm{I} / 2 \mathrm{a}$ & $0.67 \pm 0.17$ & $0.49 \pm 0.05$ \\
\hline V7 & $\mathrm{I} / 2 \mathrm{a}$ & $3.97 \pm 0.05$ & $0.44 \pm 0.06$ \\
\hline F4233 & $\mathrm{I} / 2 \mathrm{~b}$ & $0.75 \pm 0.15$ & $0.3 I \pm 0.06$ \\
\hline F4260 & $\mathrm{I} / 2 \mathrm{~b}$ & $0.67 \pm 0.04$ & $0.37 \pm 0.03$ \\
\hline ATCC 19112 & $\mathrm{I} / 2 \mathrm{c}$ & $0.62 \pm 0.12$ & $0.35 \pm 0.10$ \\
\hline ATCC 19113 & $3 a$ & $0.69 \pm 0.05$ & $0.17 \pm 0.02$ \\
\hline V47 & $3 a$ & $0.63 \pm 0.06$ & $0.32 \pm 0.08$ \\
\hline V127 & $3 a$ & $0.97 \pm 0.21$ & $0.30 \pm 0.06$ \\
\hline ATCC 19114 & $4 a$ & $0.43 \pm 0.11$ & $0.24 \pm 0.12$ \\
\hline Murray B & $4 a b$ & $1.95 \pm 0.12$ & $0.32 \pm 0.05$ \\
\hline $101 M$ & $4 b$ & $1.78 \pm 0.24$ & $0.26 \pm 0.03$ \\
\hline CAP & $4 b$ & $0.93 \pm 0.18$ & $0.25 \pm 0.09$ \\
\hline F4393 & $4 b$ & $0.65 \pm 0.07$ & $0.36 \pm 0.01$ \\
\hline F4243 & $4 \mathrm{~b}$ & $2.12 \pm 0.12$ & $0.33 \pm 0.04$ \\
\hline F1057 & $4 \mathrm{~b}$ & $1.60 \pm 0.16$ & $0.28 \pm 0.05$ \\
\hline F4264 & $4 b$ & I. $14 \pm 0.23$ & $0.28 \pm 0.11$ \\
\hline F4262 & $4 \mathrm{~b}$ & $0.85 \pm 0.08$ & $0.42 \pm 0.02$ \\
\hline F2379 & $4 b$ & $0.82 \pm 0.15$ & $0.28 \pm 0.06$ \\
\hline ATCC 19115 & $4 b$ & $1.66 \pm 0.15$ & $0.25 \pm 0.08$ \\
\hline FSL NI-227 & $4 b$ & $1.07 \pm 0.20$ & $0.33 \pm 0.08$ \\
\hline FSL NI-225 & $4 \mathrm{~b}$ & $0.93 \pm 0.18$ & $0.28 \pm 0.11$ \\
\hline F4244 & $4 \mathrm{~b}$ & $\mid .27 \pm 0.21$ & $0.38 \pm 0.08$ \\
\hline Scott A & $4 \mathrm{~b}$ & $0.56 \pm 0.06$ & $0.24 \pm 0.08$ \\
\hline FSL R2-500 & $4 \mathrm{~b}$ & $1.00 \pm 0.17$ & $0.31 \pm 0.14$ \\
\hline FSL R2-50I & $4 b$ & $1.40 \pm 0.39$ & $0.44 \pm 0.17$ \\
\hline ATCC 19116 & $4 c$ & $0.82 \pm 0.08$ & $0.24 \pm 0.08$ \\
\hline V53 & $4 c$ & $0.76 \pm 0.14$ & $0.33 \pm 0.06$ \\
\hline ATCC 19117 & $4 d$ & $0.68 \pm 0.05$ & $0.34 \pm 0.15$ \\
\hline ATCC 19118 & $4 e$ & $0.92 \pm 0.09$ & $0.44 \pm 0.03$ \\
\hline CI2-S(L) & $\mathrm{NK}^{\mathrm{a}}$ & $0.65 \pm 0.03$ & $0.30 \pm 0.05$ \\
\hline V30 & NK & $0.63 \pm 0.11$ & $0.6 I \pm 0.29$ \\
\hline V206 & NK & $3.23 \pm 0.04$ & $0.73 \pm 0.42$ \\
\hline V207 & NK & $0.50 \pm 0.06$ & $0.36 \pm 0.11$ \\
\hline ATCC 13932 & NK & $0.65 \pm 0.29$ & $0.45 \pm 0.26$ \\
\hline
\end{tabular}

Notes: ${ }^{2} \mathrm{Lm} 404$ polyclonal antibody was diluted I:I,000; 'bmC639 polyclonal antibody was diluted $\mathrm{I}: 100$.

Abbreviation: NK, not known.

were produced at SynPep Corporation (Dublin, CA, USA). Anti-internalin B (Lm404) and anti-ActA (LmC639) antibodies were also produced in rabbits raised in a specific pathogenfree environment (two rabbits for each antigen) at Lampire Biological Laboratories (Pipersville, PA, USA). Pre-immune serum from each rabbit was found to be negative when tested against Listeria species before the start of the immunization regimen. The antibody titers were determined using synthetic peptides and whole cells as an antigen in ELISA.

Antibodies (immunoglobulin $\mathrm{G}$ fractions) from the serum were purified by protein A affinity liquid chromatography. Briefly, $2 \mathrm{~mL}$ of serum from each sample was purified on a protein A column using an ÄKTA prime unit (Amersham Pharmacia Biotech AB, Uppsala, Sweden). Undiluted samples were loaded onto the column with $20 \mathrm{mM}$ phosphate-buffered saline ( $\mathrm{pH}$ 7.4) and eluted with $0.1 \mathrm{M}$ glycine ( $\mathrm{pH}$ 2.4). The eluent was collected, $\mathrm{pH}$-adjusted to 7.0 with $1 \mathrm{M}$ Tris, and stored at $4^{\circ} \mathrm{C}$ with $1 \%$ bovine serum albumin and $0.01 \%$ thimerosal.

\section{Act $A$ and internalin $B$ purification}

His-tagged ActA protein was purified from chloramphenicolresistant $L$. monocytogenes DP-L2723 $3^{31}$ as described elsewhere ${ }^{28}$ using a 70239-3 His-Bind ${ }^{\circledR}$ purification kit (Novagen, Madison, WI, USA). Fractions were analyzed by Western blot to confirm purification. The final protein concentration was determined using the 23236 Better Bradford assay kit (Pierce). Internalin B was purified from an internalin B-expressing E. coli strain BL21 (DE3) containing pET28b-129 using the His-Bind purification kit as described previously. ${ }^{32}$ These preparations were used as controls in Western blot assays.

\section{Reaction profile of polyclonal antibodies to synthetic peptides and bacteria by indirect ELISA}

Bacterial cells grown in brain heart infusion broth for 20 hours were harvested by centrifugation $(9,300 \times g$ for 10 minutes) and resuspended in equal volumes of $0.1 \mathrm{M}$ carbonate coating buffer ( $\mathrm{pH} 9.6$ ) to yield a final concentration of $1 \times 10^{9}$ colony-forming units per $\mathrm{mL} .{ }^{33}$ Peptides were diluted in $0.1 \mathrm{M}$ carbonate coating buffer ( $\mathrm{pH} 9.6$ ) to yield a final concentration of $150 \mu \mathrm{g} / \mathrm{mL}$. One hundred microliters of the bacteria or the peptides was dispensed per well into a 96-well microtiter plate (Dynex, Chantilly, VA, USA) and stored overnight at $4^{\circ} \mathrm{C}$. ELISA was performed as described previously ${ }^{34}$ using affinity-purified rabbit polyclonal antibodies, a secondary goat anti-rabbit immunoglobulin G-peroxidase conjugate antibody (Jackson ImmunoResearch Laboratories, West Grove, PA, USA), and o-Phenyldiamine substrate (Sigma-Aldrich, St Louis, MO, USA).

\section{SDS-PAGE and Western blot analysis of surface protein extracts from Listeria}

Fifteen milliliters of Listeria cultures were grown in brain heart infusion broth at $37^{\circ} \mathrm{C}$ for 18 hours. Cell surface 
proteins were extracted using Tris-HCL buffer as described before $^{35}$ and quantified by Bradford assay. Lack of contamination of surface proteins with intracellular proteins were verified by PepC assay. ${ }^{35}$ Proteins $(2.5 \mu \mathrm{g} /$ well $)$ were separated using sodium dodecyl sulfate polyacrylamide gel electrophoresis (SDS-PAGE) gel (7.5\% acrylamide) and blotted onto an Immobilon-P membrane (Millipore, Bedford, MA, USA). The membranes were blocked with $5 \%$ bovine serum albumin (Sigma-Aldrich) overnight at $4^{\circ} \mathrm{C}$ and washed four times with phosphate-buffered saline-Tween 20 (PBS-T, $0.5 \%)$. The antibodies were diluted in phosphate-buffered saline and incubated with the membrane at $37^{\circ} \mathrm{C}$ for one hour. The membranes were washed four times with PBS-T followed by incubation for one hour with goat-anti rabbit immunoglobulin G-peroxidase conjugate (1:5,000, Bio-Rad Laboratories Inc., Hercules, CA, USA). After washing three times with phosphate-buffered saline, the substrate containing diaminobenzidine tetrahydrochloride (Sigma-Aldrich) was added and allowed to react for 10 minutes. ${ }^{34}$

\section{Results}

\section{L. monocytogenes proteomic analysis and peptide selection}

Based on the comparative genome sequence of L. monocytogenes and L. innocua, nine of the 22 proteins were selected (Table 1); their amino acid sequences were collected from the database and their hydropathy profile and transmembrane topology were predicted using the ProtScale and TMpred software programs. For the internalin proteins $\mathrm{A}, \mathrm{B}$, and $\mathrm{H}$, the predicted $\mathrm{N}$-terminal transmembrane segments were located in amino acids 6-27, 11-31, and 7-26, respectively. Internalin B had no predicted C-terminal transmembrane segment, while amino acids 775-792 of internalin A and 524-541 of internalin B were predicted to be membrane spanning regions. Internalin $\mathrm{H}$ had one additional predicted transmembrane segment between amino acids 75 and 97. ActA had both an N-terminal and a C-terminal predicted transmembrane segment at 9-29 and 614-630, respectively. The $\mathrm{N}$-terminal and $\mathrm{C}$-terminal transmembrane segments for the other proteins were as follows: Lmo0460 (8-27, 172-192), Lmo1290 (internalin K; 6-31, 577-594), Lmo1115 (1-18, 835-854), Lmo2026 (5-23, 600-618) and Lmo2085 (4-20, 542-559). The selected peptide segments were predicted to be hydrophilic and possibly located outside the cytoplasmic membrane. The selected peptides showed no homology with proteins from other Listeria species or other microorganisms when searched against the National Center for Biotechnology Information BLASTP database.

\section{Reaction of polyclonal antibodies to the synthetic peptides or whole cell antigens}

Purified antibodies obtained from antisera collected from third bleeding were tested for antibody reaction titer with prospective peptide antigen and whole cells. All but one antibody (Lm406) had a high titer with respective peptide antigens, indicating successful production of peptide-reactive antibodies (Table 1). No antibody was detected against Lm406, so no further experiments were conducted with this antibody. The ELISA titration data indicated that the peptide antigens were able to induce the immune system to allow successful production of antibodies. In contrast with this, six of eight antibodies showed weak antibody titration (160 titer) against whole live cells of $L$. monocytogenes while two (Lm404 and Lm407) had an antibody titer of 640, indicating that more antibody-reactive epitopes for Lm404 and Lm407 were surface-expressed compared with the other tested antibodies.

\section{Reaction profiles for polyclonal antibodies with different bacterial cultures}

All polyclonal antibodies were tested against a panel of eight Listeria species and four non-Listeria species. The Lm404 polyclonal antibody showed a strong reaction with two of the three L. monocytogenes cultures but showed a weaker reaction with other Listeria species (Table 2). All other antibodies showed little difference between the reaction with L. monocytogenes and the other Listeria species tested. A high reaction (Abs490>1.3) with E. coli and Salmonella enterica serovar Enteritidis was observed with all nine antibodies. Upon further analysis of protein A-purified preimmune sera, it was determined that background antibodies reacted with a wide spectrum of bacteria including E. coli and Salmonella. ${ }^{36}$ Attempts to purify the antibodies with an E. coli lysate column, whole cell cross-adsorption, and affinity purification with the target peptide failed to improve the results (data not shown).

Two of the eight antibodies (Lm404 and LmC639) were further tested against 41 L. monocytogenes strains in indirect ELISA (Table 3). Antibody reactions were grouped into three categories, ie, high ( $\geq 1.000)$, medium $(0.500-0.990)$, and low $(<0.499$, Figure 1). The reaction pattern for Lm404 was $29.3 \%, 68.3 \%$, and $2.4 \%$, falling into the high, medium, and low categories, respectively. LmC639 had an overall low reaction $(90 \%)$ with all the tested strains. Only $9.8 \%$ were in the combined medium and high categories. 


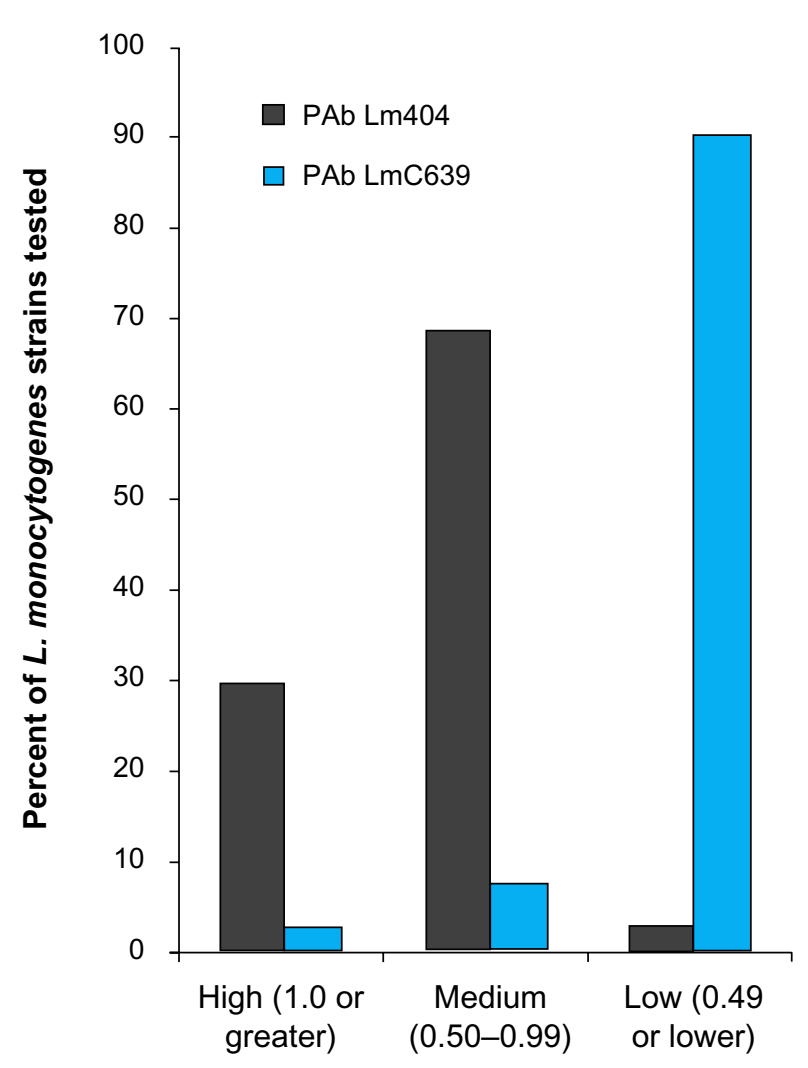

\section{Reaction intensity}

Figure I Reaction profiles of Lm404 and LmC639 polyclonal antibody to 4I Listeria monocytogenes strains. Enzyme-linked immunosorbent assay values are grouped in high ( $\geq 1.000)$, medium (0.500-0.999), and low ( $\leq 0.499)$ categories.

Abbreviation: PAb, polyclonal antibody.

\section{Western blot analysis}

To confirm if the antibodies react with their respective target antigens, Western blot analysis was done on the surface protein extracts from all eight Listeria species. The Lm404 polyclonal antibody showed reaction with the targeted $63 \mathrm{kDa}$ internalin B (Figure 2A) and the LmC639 polyclonal antibody (Figure 2B) showed reaction with its target protein band of $90 \mathrm{kDa}$ (ActA) present only in L. monocytogenes. This antibody also showed mild crossreaction with some other protein bands. As positive controls, these two antibodies showed reaction with affinity purified recombinant internalin B and ActA, confirming the specific nature of these two antibodies (Figure 2C). Western blot analysis with the remainder of the antibodies revealed reaction with multiple protein bands from different Listeria species. The Lm407 and Lm408 polyclonal antibodies showed reaction with the target protein bands of 63 $\mathrm{kDa}$ (Lmo2026 peptidoglycan binding protein) and $56 \mathrm{kDa}$ (Lmo2085 peptidoglycan binding protein) and also reacted with several additional protein bands from other Listeria species (Figure 3A and B). This is not surprising since this is a common protein shared by most Listeria species, and certain amino acids (epitopes) in the peptide sequence used are possibly present in other Listeria species. Likewise, the LmH548 polyclonal antibody showed a reaction with the target protein bands of $55 \mathrm{kDa}$ (internalin $\mathrm{H}$ ); however, it also reacted with several additional protein bands from other Listeria species (data not shown). The Lm405 polyclonal antibody (Lmo0460, a $69 \mathrm{kDa}$ putative membrane protein) did not show any reaction with the target protein band (Figure 3C). Likewise, the Lm406 polyclonal antibody (Lmo1115, a $86 \mathrm{kDa}$ hypothetical protein), the LmA800 polyclonal antibody ( $80 \mathrm{kDa}$ internalin A), and the Lm1290 polyclonal antibody (Lmo1290, $60 \mathrm{kDa}$ internalin K) ${ }^{37} \mathrm{did}$ not also show any reactions with their targeted protein bands (data not shown).

\section{Discussion}

Availability of a genome sequence of microbes and comparative genome sequence analysis has made it possible to determine genetic and phenotypic differences between species within a genus. ${ }^{25,38}$ Rapid detection of $L$. monocytogenes from foods or food contact surfaces continues to challenge the food industry. Rapid immunological methods could be improved if a more specific antibody for $L$. monocytogenes existed. Through the use of genomics and proteomics, the present research attempted to develop L. monocytogenesspecific antibodies targeted against unique peptide sequences from surface proteins of L. monocytogenes. The genomic and proteomic analysis allowed us to select peptide epitopes as potential antigens for production of antibodies. ${ }^{27}$ Despite detailed analysis, not all of the peptides produced desirable antibody responses. For example, the Lm406 polyclonal antibody developed against the peptide of unknown protein Lmo1115 failed to produce a strong antibody response when tested against the peptide. The low reaction indicated that either peptide synthesis, the immunization process, or peptide selection failed. Although the remaining eight antibodies showed a high titer to their respective peptides, only two (the Lm404 and LmC639 polyclonal antibodies) showed specific reaction to the targeted protein in Western blot. Of the remaining six, some reacted with target antigen along with several more protein bands (see Western blot for the Lm407 and Lm408 polyclonal antibodies, Figure 3A and B), while the Lm 405 polyclonal antibody developed against the $69 \mathrm{kDa}$ putative membrane protein did not show any reaction with its target protein band (Figure 3C). In a previous study, the Lm404 and LmC639 polyclonal antibodies were used to monitor differential expression of internalin $\mathrm{B}$ and ActA when grown in different Listeria-selective enrichment broths. ${ }^{14}$ The lack of specific reaction of other 


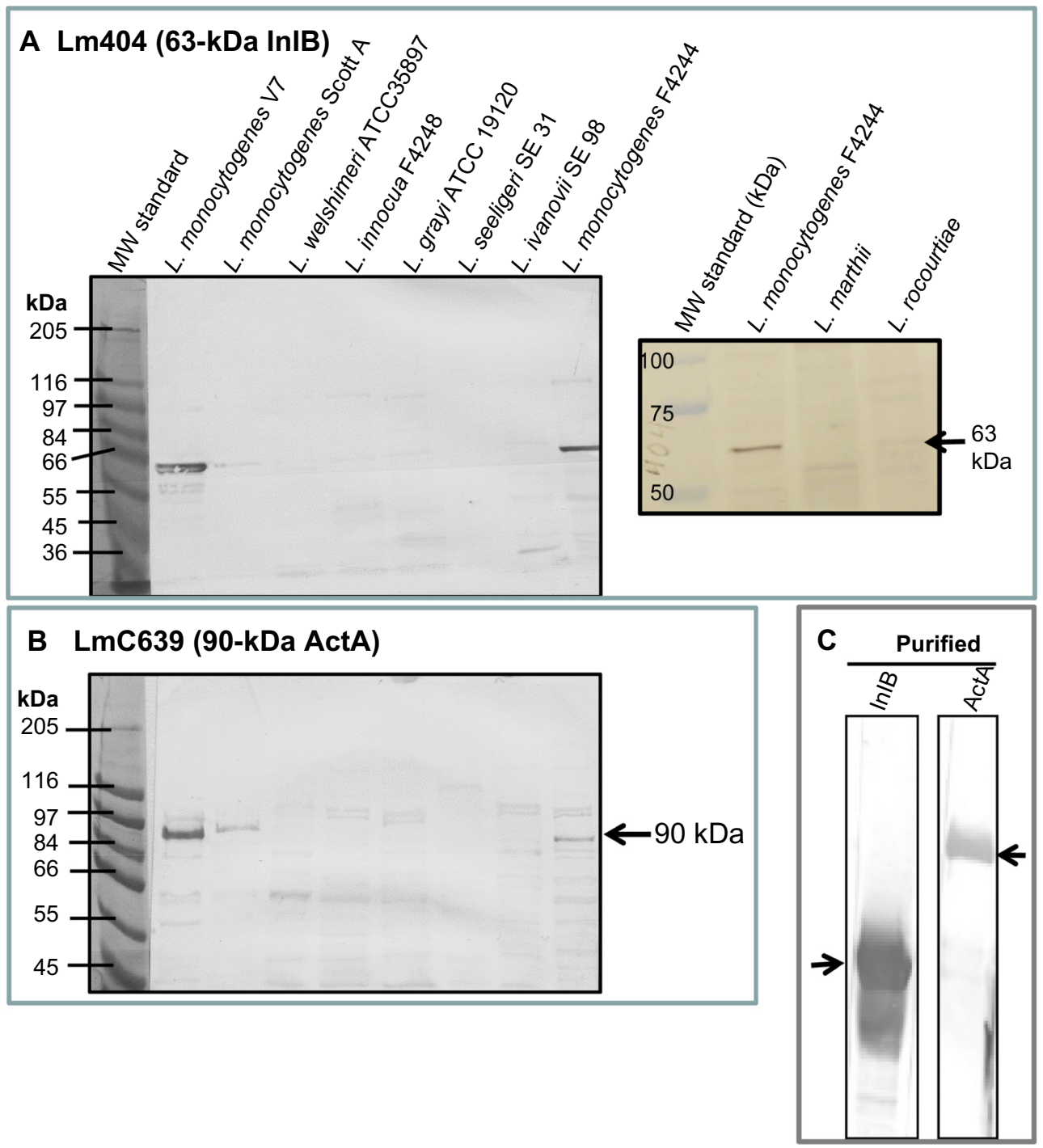

Figure 2 Western blot analysis of Listeria surface proteins with (A) Lm404 polyclonal antibody developed against internalin B (63 kDa) and (B) LmC639 polyclonal antibody developed against ActA (90 kDa). (C) Purified internalin B (63 kDa band) and ActA $(90 \mathrm{kDa})$ are included as controls.

Abbreviations: $M W$, molecular weight; InIB, internalin $B$; Act $A$, actin polymerization.

antibodies could be due to denaturation of the target protein. When the Lm404 and LmC639 polyclonal antibodies were tested with a large panel of $L$. monocytogenes strains, the Lm404 polyclonal antibody showed an overall strong reaction while the LmC639 polyclonal antibody was weak. The weak reaction for the $\mathrm{LmC639}$ polyclonal antibody was due to the lower expression of ActA under the current growth conditions (brain heart infusion broth). In an earlier study, we verified that ActA expression was indeed very poor in all 13 serovars of L. monocytogenes when grown in brain heart infusion broth and Luria-Bertani broth. However, increased expression was noticed when the same cultures were grown in Listeria-selective enrichment broths, ie, buffered Listeria enrichment broth, University of Vermont medium, and Fraser broth. ${ }^{14}$ Greene and Freitag ${ }^{39}$ showed that medium with glucose concentrations $5 \mathrm{mM}$ or higher decreased expression of ActA. Since brain heart infusion has a glucose concentration of $11 \mathrm{mM}$, changing to a low glucose medium could improve expression of ActA, yielding higher reaction values.

All of the antibodies showed high cross-reaction with E. coli and Salmonella in ELISA. The protein database was searched to identify all of the peptides and none showed any homology with proteins from other bacteria, so the antibody reaction to these microorganisms was unexpected. After examining the preimmune sera from several rabbits used for antibody production, it was obvious that the cross-reactive antibodies were already present before immunization. ${ }^{36}$ Use of rabbits raised in a specific pathogen-free environment would be able to reduce crossreaction problems with nontarget bacteria; however, we observed that sera from several rabbits claimed to be raised 


\section{A $\quad \operatorname{Lm} 407(63 \mathrm{kDa})$}

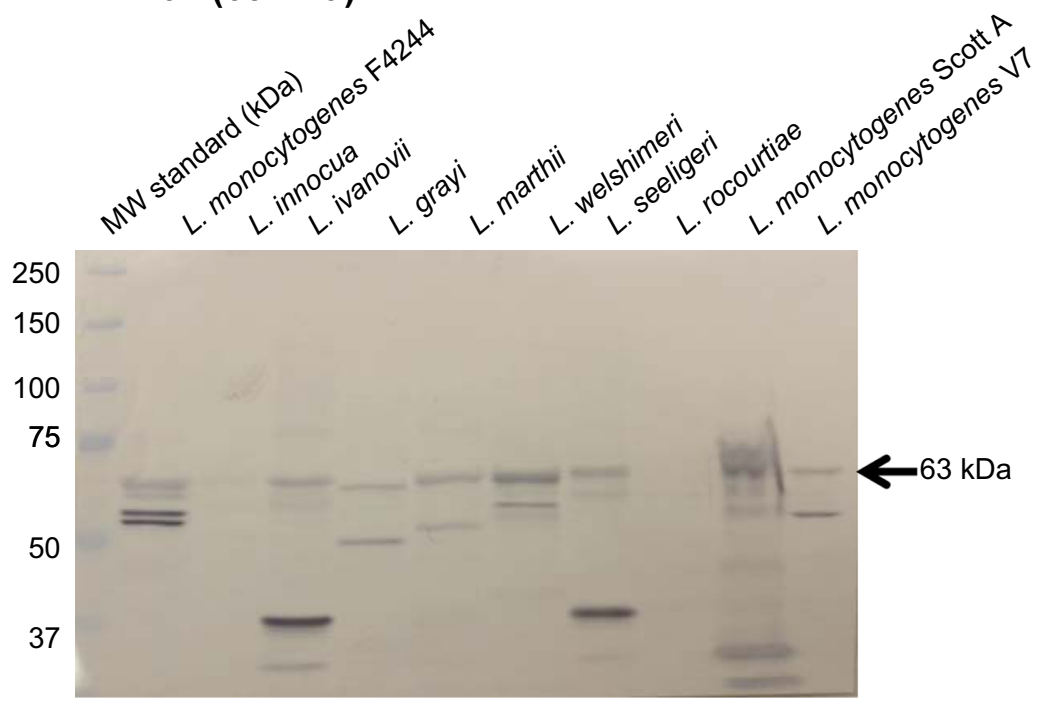

\section{B Lm408 (56 kDa)}

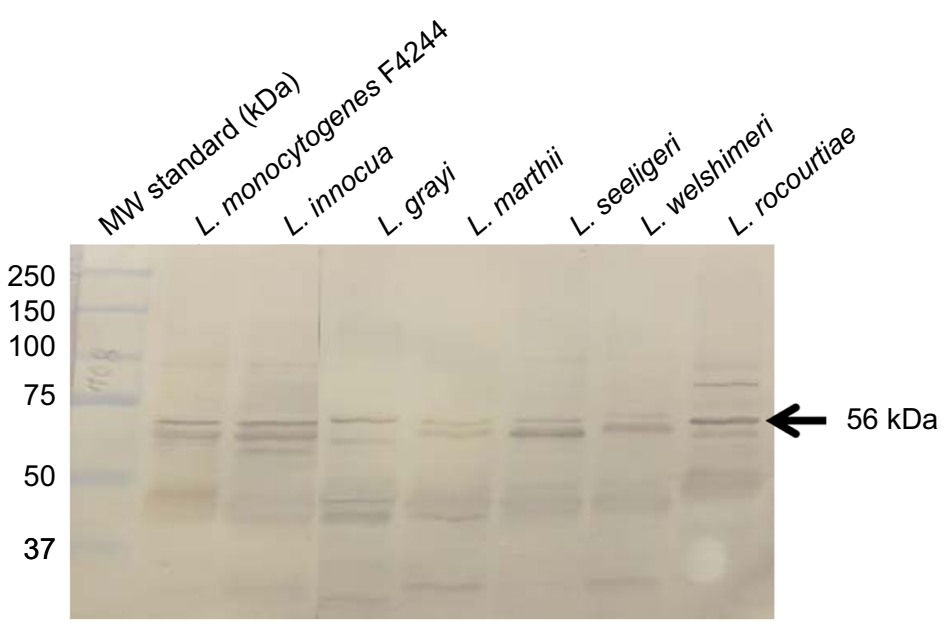

\section{C $\operatorname{Lm} 405(69 \mathrm{kDa})$}

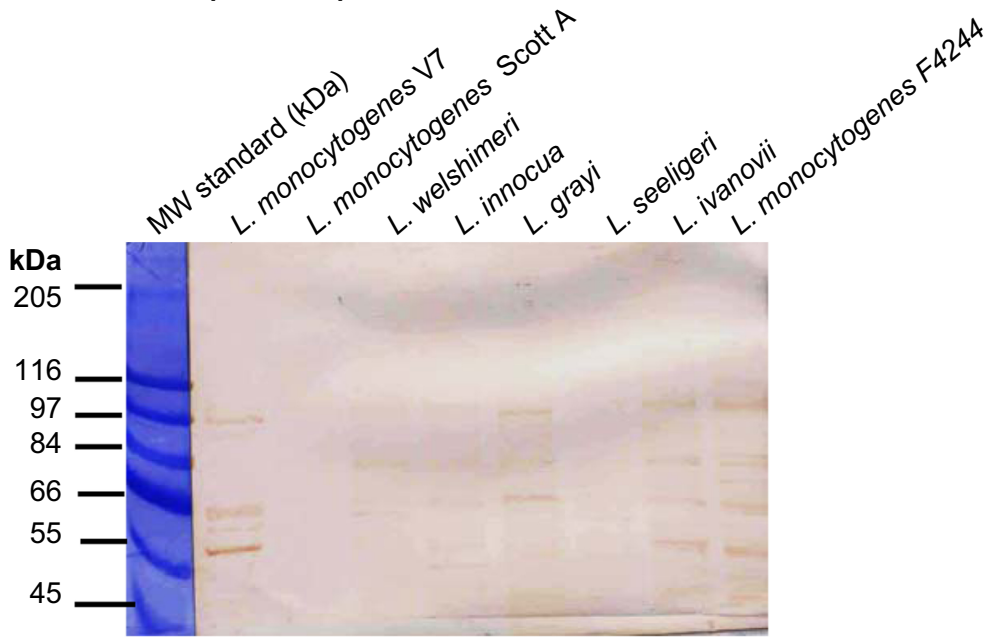

Figure 3 Western blot analysis of Listeria surface proteins with (A) Lm407 polyclonal antibody, (B) Lm408 polyclonal antibody, and (C) Lm405 polyclonal antibody. Lm407 and $\mathrm{Lm} 408$ polyclonal antibodies reacted with target proteins and also with other proteins while Lm405 polyclonal antibody showed reaction mostly with nontarget antigens. Abbreviation: MW, molecular weight. 
in a specific pathogen-free environment also showed strong reaction against Proteus vulgaris, Salmonella enterica serovar Typhimurium, Bacillus cereus, Corynebacterium glutamicum, E. coli, and Enterococcus faecalis. ${ }^{36}$ Attempts to remove cross-reactive antibodies by further purification were unsuccessful. However, cross-reaction to nontarget microorganisms can be overcome by using appropriate selective enrichment broth during preparation of samples before immunoassay.

\section{Conclusion}

All polyclonal antibodies except for the Lm406 polyclonal antibody (Lmo1115) showed specific reaction with the peptide antigens, indicating that comparative genomics could be used as a tool to select pathogen-specific antigen for antibody production. Only the Lm404 (internalin B) and LmC639 (ActA) polyclonal antibodies showed specific reactions for the protein from which the peptides were chosen and also showed some minor nonspecific reactions with other protein bands. The remaining polyclonal antibodies reacted with multiple protein bands. Based on Western blot results, the internalin B and ActA peptides appear to be the most promising targets for production of L. monocytogenes-specific antibodies. However, LmC639 (ActA) showed weaker reactions in ELISA, indicating epitope access may be obstructed in whole cells under the tested growth conditions. All antibodies, including the Lm404 and LmC639 polyclonal antibodies, showed strong reactions with E. coli and Salmonella in ELISA. This is because the rabbits had a high background antibody titer against these microbes. Monoclonal antibodies could be produced to avoid background antibodies.

\section{Acknowledgments}

This research was supported by a cooperative agreement with the Agricultural Research Service of the US Department of Agriculture (1935-42000-072-02G), the Center for Food Safety and Engineering at Purdue University, and the National Cattlemen's Beef Association.

\section{Disclosure}

The authors report no conflicts of interest in this work.

\section{References}

1. Donnelly CW. Listeria monocytogenes: a continuing challenge. Nutr Rev. 2001;59:183-194.

2. McCollum JT, Cronquist AB, Silk BJ, et al. Multistate outbreak of listeriosis associated with cantaloupe. N Engl J Med. 2013;369:944-953.

3. Centers for Disease Control and Prevention. Public health dispatch: outbreak of listeriosis-Northeastern United States, 2002. MMWR Morb Mortal Weekly Rep. 2002;51:950-951.
4. Cosgrove S, Cronquist A, Wright G, et al. Multistate outbreak of listeriosis associated with Jensen Farms cantaloupe - United States, August-September 2011. MMWR Morb Mortal Wkly Rep. 2011;60: 1357-1358.

5. Silk BJ, Mahon BE, Griffin PM, et al. Vital signs: listeria illnesses, deaths, and outbreaks-United States, 2009-2011. MMWR Morb Mortal Wkly Rep. 2013;62:448-452.

6. Jackson KA, Biggerstaff M, Tobin-D'Angelo M, et al. Multistate outbreak of Listeria monocytogenes associated with Mexican-style cheese made from pasteurized milk among pregnant, Hispanic women. J Food Prot. 2011;74:949-953.

7. Hitchins AD. Listeria monocytogenes. In: Merker RL, editor. Bacteriological Analytical Manual. 8th ed. Arlington, VA, USA: AOAC International; 1998.

8. Banada PP, Bhunia AK. Antibodies and immunoassays for detection of bacterial pathogens. In: Zourob M, Elwary S, Turner A, editors. Principles of Bacterial Detection: Biosensors, Recognition Receptors and Microsystems. Manchester, UK: Cambridge University; 2008.

9. Kim SH, Park MK, Kim JY, et al. Development of a sandwich ELISA for the detection of Listeria spp. using specific flagella antibodies. J Vet Sci. 2005;6:41-46.

10. Yu KY, Noh Y, Chung M, et al. Use of monoclonal antibodies that recognize p60 for identification of Listeria monocytogenes. Clin Diagn Lab Immunol. 2004;11:446-451.

11. Datta A, Kothary M. Effects of glucose, growth temperature, and $\mathrm{pH}$ on listeriolysin O production in Listeria monocytogenes. Appl Environ Microbiol. 1993;59:3495-3497.

12. Geng T, Kim KP, Gomez R, et al. Expression of cellular antigens of Listeria monocytogenes that react with monoclonal antibodies C11E9 and EM-7G1 under acid-, salt- or temperature-induced stress environments. J Appl Microbiol. 2003;95:762-772.

13. Jaradat ZW, Bhunia AK. Glucose and nutrient concentrations affect the expression of a 104-kilodalton Listeria adhesion protein in Listeria monocytogenes. Appl Environ Microbiol. 2002;68:4876-4883.

14. Lathrop AA, Banada PP, Bhunia AK. Differential expression of InlB and ActA in Listeria monocytogenes in selective and nonselective enrichment broths. J Appl Microbiol. 2008;104:627-639.

15. Soni KA, Nannapaneni R, Tasara T. An overview of stress response proteomes in Listeria monocytogenes. Agric Food Anal Bacteriol. 2011;1:66-85.

16. Erdenlig S, Ainsworth AJ, Austin FW. Production of monoclonal antibodies to Listeria monocytogenes and their application to determine the virulence of isolates from channel catfish. Appl Environ Microbiol. 1999;65:2827-2832.

17. Bhunia AK, Johnson MG. Monoclonal antibody specific for Listeria monocytogenes associated with a 66-kilodalton cell surface antigen. Appl Environ Microbiol. 1992;58:1924-1929.

18. Solve M, Boel J, Norrung B. Evaluation of a monoclonal antibody able to detect live Listeria monocytogenes and Listeria innocua. Int J Food Microbiol. 2000;57:219-224.

19. Wieckowska-Szakiel M, Bubert A, Rozalski M, Krajewska U, Rudnicka W, Rozalska B. Colony-blot assay with anti-p60 antibodies as a method for quick identification of Listeria in food. Int $J$ Food Microbiol. 2002;72:63-71.

20. Kathariou S, Mizumoto C, Allen RD, Fok AK, Benedict AA. Monoclonal antibodies with a high degree of specificity for Listeria monocytogenes serotype 4b. Appl Environ Microbiol. 1994;60: 3548-3552.

21. Paoli GC, Chen CY, Brewster JD. Single-chain Fv antibody with specificity for Listeria monocytogenes. J Immunol Methods. 2004;289: 147-155.

22. Leonard P, Hearty S, Wyatt G, Quinn J, O'Kennedy R. Development of a surface plasmon resonance -based immunoassay for Listeria monocytogenes. J Food Prot. 2005;68:728-735.

23. Mendonca M, Conrad N, Conceicao F, et al. Highly specific fiber optic immunosensor coupled with immunomagnetic separation for detection of low levels of Listeria monocytogenes and L. ivanovii. BMC Microbiol. 2012;12:275. 
24. Doumith M, Buchrieser C, Glaser P, Jacquet C, Martin P. Differentiation of the major Listeria monocytogenes serovars by multiplex PCR. JClin Microbiol. 2004;42:3819-3822.

25. Glaser P, Frangeul L, Buchrieser C, et al. Comparative genomics of Listeria species. Science. 2001;294:849-852.

26. Nelson KE, Fouts DE, Mongodin EF, et al. Whole genome comparisons of serotype $4 \mathrm{~b}$ and $1 / 2 \mathrm{a}$ strains of the food-borne pathogen Listeria monocytogenes reveal new insights into the core genome components of this species. Nucleic Acids Res. 2004;32:2386-2395.

27. Lathrop AA. Development of Listeria monocytogenes specific antibodies using a proteomics/genomics approach and expression of antibodyspecific antigens InlB and ActA under different environments. West Lafayette, IN, USA: Purdue University; 2005. Available from: http:// docs.lib.purdue.edu/dissertations/AAI3287396/. Accessed April 4, 2014.

28. Upadhyaya A, Chabot JR, Andreeva A, Samadani A, van Oudenaarden A. Probing polymerization forces by using actin-propelled lipid vesicles. Proc Natl Acad Sci U S A. 2003;100:4521-4526.

29. Braun L, Dramsi S, Dehoux P, Bierne H, Lindahl G, Cossart P. InIB: an invasion protein of Listeria monocytogenes with a novel type of surface association. Mol Microbiol. 1997;25:285-294.

30. Kyte J, Doolittle RF. A sample method for displaying the hydropathic character of a protein. J Mol Biol. 1982;157:105-132.

31. Welch MD, Rosenblatt J, Skoble J, Portnoy DA, Mitchison TJ. Interaction of human Arp2/3 complex and the Listeria monocytogenes ActA protein in actin filament nucleation. Science. 1998;281: 105-108.
32. Jagadeesan B, Koo OK, Kim KP, et al. LAP, an alcohol acetaldehyde dehydrogenase enzyme in Listeria promotes bacterial adhesion to enterocyte-like Caco-2 cells only in pathogenic species. Microbiology. 2010;156:2782-2795.

33. Bhunia AK, Ball PH, Fuad AT, Kurz BW, Emerson JW, Johnson MG. Development and characterization of a monoclonal antibody specific for Listeria monocytogenes and Listeria innocua. Infect Immun. 1991;59: 3176-3184.

34. Lathrop AA, Jaradat ZW, Haley T, Bhunia AK. Characterization and application of a Listeria monocytogenes reactive monoclonal antibody C11E9 in a resonant mirror biosensor. J Immunol Methods. 2003;281: 119-128.

35. Burkholder KM, Kim KP, Mishra K, et al. Expression of LAP, a SecA2dependent secretory protein, is induced under anaerobic environment. Microbes Infect. 2009;11:859-867.

36. Lathrop AA, Huff K, Bhunia AK. Prevalence of antibodies reactive to pathogenic and nonpathogenic bacteria in preimmune serum of New Zealand white rabbits. J Immunoassay Immunochem. 2006;27: 351-361.

37. Neves D, Job V, Dortet L, Cossart P, Dessen A. Structure of internalin InlK from the human pathogen Listeria monocytogenes. J Mol Biol. 2013;425:4520-4529.

38. Hain T, Steinweg C, Chakraborty T. Comparative and functional genomics of Listeria spp. J Biotechnol. 2006;126:37-51.

39. Greene SL, Freitag NE. Negative regulation of PrfA, the key activator of Listeria monocytogenes virulence gene expression, is dispensable for bacterial pathogenesis. Microbiology. 2003;149 Pt 1:111-120.
Antibody Technology Journal

\section{Publish your work in this journal}

Antibody Technology Journal is international, peer-reviewed, open access journal publishing original research, reports, reviews and commentaries on all areas of antibody technology. The manuscript management system is completely online and includes a very quick and fair
Dovepress

peer-review system. Visit http://www.dovepress.com/testimonials.php to read real quotes from published authors. 